\title{
TECHNICAL NOTE: PRELIMINARY COMMUNICATION \\ A TRIDIGITAL DYNAMIC ORTHOSIS FOR TETRAPLEGIC PATIENTS
}

\author{
By Paul Dollfus, M.D. and Michel Oberlé \\ Centre de Réadaptation de Mulhouse, France
}

Summary. A new orthosis using the same principles as the tridigital pinch for forearm amputees is presented. The forward movement of the shoulders activates a cable which allows the two first fingers to grasp an object firmly against the thumb which is maintained in half opposition. This device can be particularly useful for low cervical lesions with no or weak finger flexors.

Key words: Tetraplegia; Upper limb orthosis.

ThIS very light orthosis uses the same principle as the 'tridigital pinch' commonly used by forearm amputees. It has a similar action to a deep finger flexor tendon (Fig. I) common to the first two fingers, the thumb being placed in semi-opposition. It enables a person with a low cervical lesion (C7-C8) with good wrist movements to use these to grip and hold an object firmly. The wrist movements are biomechanically extremely useful for dexterity (pronation, supination, flexion, extension, lateral and medial deviation). The distribution of sensation covering the thumb and the two first fingers is usually fair to normal, allowing a very useful sensory feedback. A forward movement of one or both shoulders is enough to activate the pinching action. The orthosis can be put on and off independently. Some help however is needed to put on the shoulder harness which can easily be removed by the person (Figs. 2 and 3 ).

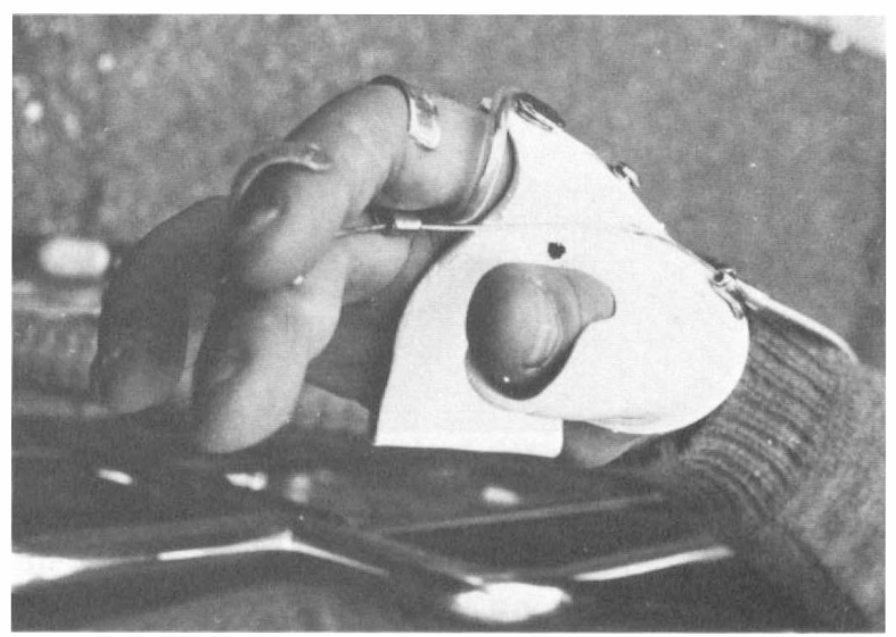

FIG. I

Note position in semi-opposition of the thumb and active 'tendon-cable'. 


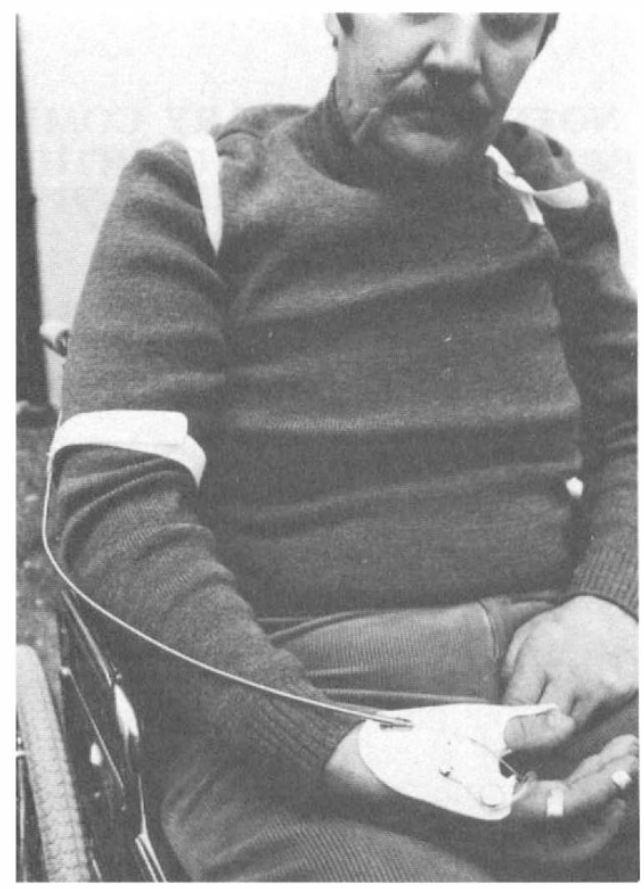

FIG. 2

Shows the shoulder harness-cable-orthosis system.

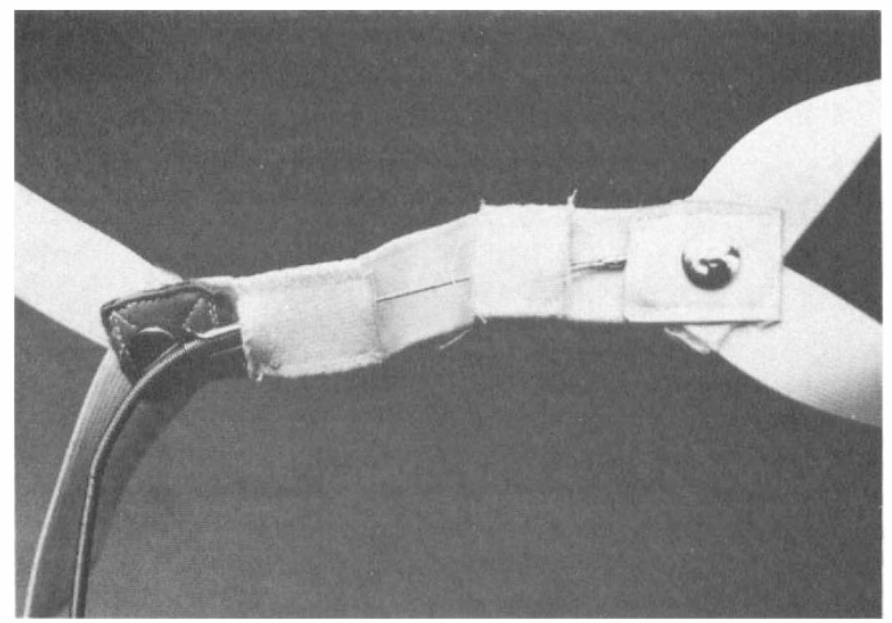

FIG. 3

Detailed picture of the harness and cable at rest (left hand orthosis).

\section{Material and Technique}

The orthosis itself is custom-made from a pattern of Formasplint ${ }^{\circledR}$ or trans- 


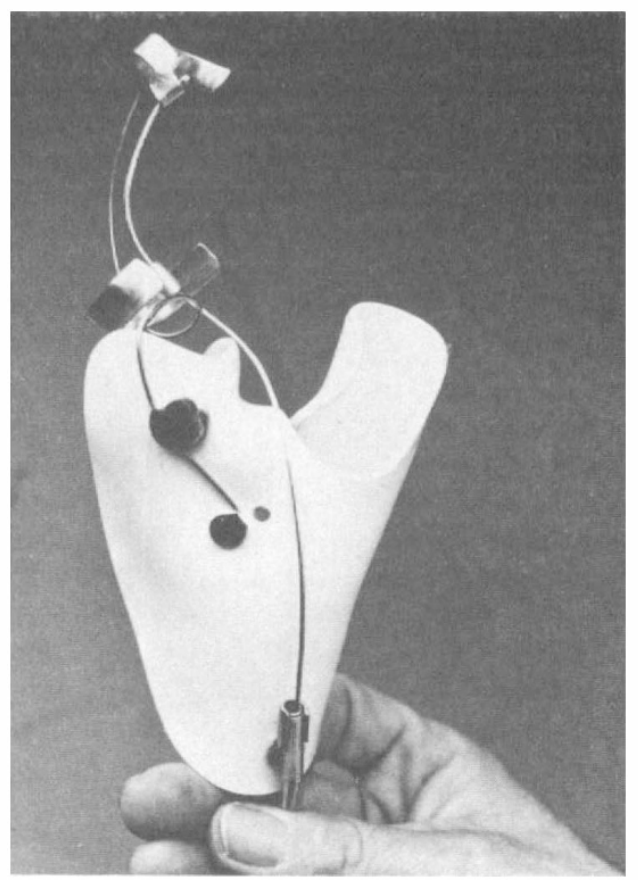

FIG. 4

Left hand orthosis showing the position of the 'extension wire' and the 'tendon cable'.

parent Darvic ${ }^{\circledR}$. After softening by heat, the pattern is adjusted on a positive plaster cast of the hand. The finger pieces are welded to a stainless steel piano-wire which maintains a passive extension. The flexion movement is carried out by a bicycle cable soldered to the tip of the piano-wire at the level of the distal phalanx and slides through a channel in the proximal finger piece (Fig. 4). This cable is connected to the shoulder harness through a bicycle cable sheath which is secured distally on the orthosis itself and proximally at the level of the harness. The cost of the material is estimated at approximately Io pounds. The system takes approximately 7-8 hours to make.

Several attempts have been described in the literature concerning dynamic orthoses for tetraplegics. This appliance has been tried out by two tetraplegics who are helping us with further developments and evaluation during its daily use at the Center and soon at home. It is only a preliminary attempt to try and solve the problem of gripping and pinching with a faire or full motor control of the wrist. The problem of aesthetics still remains. This is very important as many tetraplegics have given up their dynamic orthosis for this reason. Lately we have used a transparent material such as Darvic ${ }^{\mathbb{R}}$. Even if tetraplegics use this orthosis only for work or certain activities we think it might be a good idea to continue the research with their active participation and suggestions. We intend to use the same principle for higher lesions with the help of a motor and myoelectric controls, the energy being supplied by the wheelchair batteries. 


\section{RÉSUMÉ}

Une orthèse utilisant le même principe que la pince tridigitale chez les amputés est présentée. Elle permet de pincer avec force un objet tout en gardant la force et la préhension utilisables des mouvements du poignet très souvent préservée dans les lésions cervicales basses en $\mathrm{C}_{7}$ ou C8.

\section{ZUSAMMENFASSUNG}

Eine Orthesis, abgelenkt von dem Princip der Dreidigitiszange beim Amputierte, activiert bei den Schultern, wurde vorgestellt. Es erlaubt eine gute benutzbare Zange beim Tetraplegiker von $\mathrm{C}_{7}$-C8 Höhe. 